(2) Open Access Full Text Article

\title{
Impact of an emergency medicine clerkship on students' perceptions of emergency medicine
}

This article was published in the following Dove Press journal:

Advances in Medical Education and Practice

II February 2015

Number of times this article has been viewed

\section{Sangeeta Lamba' \\ Roxanne Nagurka' \\ Bart Holland ${ }^{2}$ \\ Sandra Scott'}

'Department of Emergency Medicine, 2Department of Preventive Medicine, Rutgers New Jersey Medical School, Newark, NJ, USA
Correspondence: Roxanne Nagurka Department of Emergency Medicine, Rutgers New Jersey Medical School, I50 Bergen Street, Newark, NJ 07I0I, USA

Email nagurkrm@gsbs.rutgers.edu
Purpose: To determine the impact of an emergency medicine (EM) clerkship on senior (4th year) medical students' perceptions of the EM specialty.

Subjects and methods: This was a pre/posttest observational study in a mandatory 4-week EM clerkship. Students were anonymously surveyed pre- and postclerkship regarding perceptions of EM. The survey used 24 statements grouped across four domains: 1) student EM clerkship expectations/experiences, 2) perceptions regarding EM physicians, 3) perceptions regarding patients in the emergency department (ED), and 4) EM as a desirable career. Data were analyzed using paired-sample $t$-tests, and comparisons made using McNemar's $\chi^{2}$ test.

Results: A total of 385 of 407 students (94.6\%) completed the pre- and postclerkship survey. There was no significant difference between mean ratings before and after related to perceptions regarding EM physicians (3.71 versus 3.71), ED patients (3.80 versus 3.76), or EM as a desirable career (3.88 versus 3.84). However, ratings regarding clerkship expectations/experiences decreased ( 3.88 versus $3.56, P=0.001$ ). Of the 292 students that ranked their top three specialties in both pre- and postclerkship surveys, $46(16 \%)$ included EM as a top choice preclerkship, with 31 of these maintaining this interest postclerkship. Conversely, 12 students (5\%) became interested in EM postclerkship. Some survey-statement ratings were influenced and varied by urban versus community clerkship-rotation site.

Conclusion: A mandatory senior EM clerkship did not significantly change overall students' perceptions regarding EM. Students with an interest in EM rated domains higher than those not interested, though there may have been an overall decline in perceptions related to clerkship expectations and experiences. Larger, multisite studies may help identify aspects of the field or EM clerkship that influence a student's ultimate career choice.

Keywords: emergency medicine, clerkship, medical education

\section{Introduction}

Emergency medicine (EM) training began over 30 years ago at the University of Cincinnati, and was officially recognized as a specialty by the American Board of Emergency Medicine in 1989. ${ }^{1}$ Since its inception, the field of EM has experienced a strong interest in graduating US medical students and a rapid growth of residency programs nationwide. As of 2012, 153 accredited EM residency programs existed through the US. ${ }^{2}$ More and more medical students are expressing an interest in and ranking EM as a top specialty choice. In 2010, EM was listed as the third-most common specialty choice (behind internal medicine and pediatrics), with no unmatched residency positions in 2012.,3

EM as a specialty has experienced marked development in academia, demonstrated by an increase in academic departments, residency programs, extramural grant 
funding, and representation on medical school curriculum and promotion committees. ${ }^{3,4}$ In spite of these developments, the addition of mandatory EM clerkships still remains a slow area of growth for academic EM. ${ }^{3,4}$ Since an EM clerkship may be a student's first or only experience in the field, it is important to determine the impact of the clerkship on students' perceptions of EM and ascertain if EM's growing popularity is related to the clerkship experience. There are multiple studies in the fields of surgery, pediatrics, and psychiatry that examined the effects of a clerkship on students' perceptions of the specialty and their career intentions. ${ }^{5-10}$ However, similar research on medical students' perceptions of EM after their clerkship experience is limited. ${ }^{11,12}$ The purpose of this study is to determine the impact of an EM clerkship on fourth-year medical students' perceptions of EM physicians, emergency department (ED) patients, and the EM specialty.

\section{Subjects and methods}

We used an anonymous self-report pre- and postclerkship survey of all senior medical students participating in a mandatory 4th year EM clerkship experience (Figure S1).
The clerkship students rotate through four sites; the majority of students rotate at the study institution. Students applying for an EM residency must complete the EM clerkship during the first four blocks (each block is 4 weeks). The study took place in a large, urban, Northeastern academic hospital between October 2008 and July 2011. This study was approved by the university's institutional review board.

\section{Setting}

Students rotate in four affiliate hospital EDs. Site A is the primary rotation site and the study institution. This site is a high-volume, urban, safety-net hospital with a level 1 trauma center and dedicated psychiatric emergency services. Both sites $\mathrm{A}$ and $\mathrm{B}$ are academic hospitals located in urban areas, whereas sites $\mathrm{C}$ and $\mathrm{D}$ are community hospital level 2 trauma centers located in suburban areas.

\section{Development of the instrument}

The survey content was developed through a comprehensive review of the literature and through a consensus group of EM faculty. As shown in Table 1, it contained 24 statements in four

Table I Pre- and postclerkship ratings across domains and survey statements in each domain

\begin{tabular}{|c|c|c|c|}
\hline Domains and survey statements $(n=385)$ & $\begin{array}{l}\text { Preclerkship, } \\
\text { mean, SD }\end{array}$ & $\begin{array}{l}\text { Postclerkship, } \\
\text { mean, SD }\end{array}$ & Difference $(\mathrm{Cl})$ \\
\hline $\begin{array}{l}\text { EM clerkship expectations/experiences** } \\
\text { - hands-on learning experience } \\
\text { - an easy rotation } \\
\text { - treated with professionalism }\end{array}$ & $3.88(0.52)$ & $3.56(0.65)$ & $0.32(0.25-0.39)$ \\
\hline $\begin{array}{l}\text { EM as a desirable career } \\
\text { - future lifestyle } \\
\text { - future financial reward } \\
\text { - the opportunity to serve the underserved }\end{array}$ & $3.88(0.50)$ & $3.84(0.52)$ & $0.04(-0.01$ to 0.09$)$ \\
\hline $\begin{array}{l}\text { Perceptions regarding EM physicians } \\
\text { - have prestige in the local community } \\
\text { - respected by other physicians } \\
\text { - make less income relative to others } \\
\text { - have a flexible work schedule } \\
\text { - have a predictable work schedule } \\
\text { - have job security in the future } \\
\text { - generally satisfied with their career choice } \\
\text { - are compassionate providers } \\
\text { - have adequate patient contact } \\
\text { - trained to know technical skills and procedure } \\
\text { - trained to perform routine health care tasks } \\
\text { - deal with behavioral problems } \\
\text { - are susceptible to burnout }\end{array}$ & $3.7 I(0.40)$ & $3.71(0.44)$ & $0(-0.05$ to 0.04$)$ \\
\hline $\begin{array}{l}\text { Perceptions regarding patients in the ED } \\
\text { - have a variety of ailments } \\
\text { - often needing critical care } \\
\text { - experience improved symptoms while in ED } \\
\text { - compliant with their treatment } \\
\text { - come from a variety of cultural groups }\end{array}$ & $3.80(0.46)$ & $3.76(0.47)$ & $0.04(-0.01$ to 0.09$)$ \\
\hline
\end{tabular}

Notes: $* * P=0.00 I$. Each statement was scored on a scale of $I-5$ ( $I=$ strongly disagree, $3=$ neutral, $5=$ strongly agree).

Abbreviations: $\mathrm{Cl}$, confidence interval; EM, emergency medicine; ED, emergency department; SD, standard deviation. 
primary domains: 1) EM clerkship experiences (preclerkship expectations and perceptions regarding experiences in the postclerkship (three statements), 2) perceptions regarding characteristics of EM physicians (13 statements), 3) perceptions regarding ED patients (five statements), and 4) EM as a desirable career-related factors (three statements), in addition to demographic information. The survey statements were refined through cognitive interviews of medical students prior to the initiation of the study. Final edits were made with EM faculty consensus. All statements were scored on a scale of 1-5 (strongly disagree to strongly agree). The preclerkship survey was administered on the first day of the rotation, and was matched to a postclerkship survey on the last day of the rotation. Students self-selected a four-digit number that they wrote on a piece of paper and placed in an envelope that they sealed. They wrote their names on the envelope for distribution 4 weeks later at the end of their rotation to ensure they did not forget their self-selected four-digit number.

Composite scores were computed by summing the response for the statements in each domain and dividing by the number of questions to maintain the 5-point scale. We assessed for changes between the pre- and postclerkship responses using paired-sample $t$-tests. Our intent was to examine changes in student perceptions postclerkship; we measured strength of agreement (pre- versus postclerkship) for each item, irrespective of the direction of statements. In addition, students' interest in EM as a specialty was compared pre- and postclerkship using McNemar's $\chi^{2}$ test. For each of the questions, we looked for three independent variables that were effective in influencing the outcome: 1) site, 2) blocks, and 3) EM as a top-three specialty choice.

\section{Results}

During the study period, 407 students participated in the EM clerkship; 385 completed the pre- and postclerkship surveys for a survey-completion rate of $94.6 \%$. The mean age of respondents was 26.5 years (standard deviation 2.87); $52.6 \%$ ( 214 of 407) were male and $45.9 \%$ (187 of 407) female. Many of the medical students reported having had prior experience with the ED setting: as a patient (260 of 407, 64\%) or as a volunteer (304 of 407, 75\%). A total of 292 students also completed the open-ended statement on both the pre- and postclerkship surveys listing their top-three specialty choices. Preclerkship, 46 students (46 of 292, 16\%) declared EM as one of their top-three specialty choices. However, postclerkship, 31 of these students still expressed this ongoing interest. Out of the 246 initially non-EM-interested students, 12 students (4.9\%) expressed a new interest in EM as a specialty choice postclerkship.

We compared all students' perceptions pre- and postclerkship regarding EM. We found no statistically significant difference between pre- and postclerkship mean ratings related to the domains of desirable career factors, as well as perceptions regarding EM physicians and regarding ED patients. However, there was a statistically significant decrease in the scores for the clerkship-experience domain (Table 1).

To better understand the impact of domain scores based on an underlying interest in EM (students who selected EM as one of their top-three specialty choices), we then compared postclerkship ratings from students who expressed an interest in EM ( $n=43)$ with those that expressed no interest in EM ( $\mathrm{n}=253)$. As expected, students who were interested in EM postclerkship rated all the specialty-related domains higher than those students who were not interested in EM (Table 2). We also noted three trends regarding survey statements postclerkship: 1) students interested in EM felt they had an "easy rotation", as opposed to those who were not interested, 2) students interested in EM felt EM physicians used fewer procedural skills than those not interested, and 3) students interested in EM perceived ED patients to be compliant with their follow-up treatment more than the students not interested in EM.

When examining pre- and postclerkship statement variables by the site of rotation, we found a statistically significant $(P<0.05)$ decrease in the scores at all sites for two statements in the clerkship-experience domain: " ... hands on learning experience" and "... treated with professionalism by other providers". Conversely, scores significantly increased among

Table 2 Comparison of ratings of students interested in emergency medicine (EM) versus not interested in EM after a clerkship rotation*

\begin{tabular}{llll}
\hline Characteristics & $\begin{array}{l}\text { Interested in EM } \\
(\mathbf{n = 4 3}), \text { mean, SD }\end{array}$ & $\begin{array}{l}\text { Not interested in EM } \\
(\mathbf{n = 2 5 3}), \text { mean, SD }\end{array}$ & Difference (CI) \\
\hline EM clerkship expectations and experiences & $3.83(0.47)$ & $3.52(0.65)$ & $0.31(0.15-0.47)$ \\
EM as a desirable career & $4.02(0.36)$ & $3.82(0.49)$ & $0.20(0.08-0.32)$ \\
Perceptions regarding EM physicians & $3.84(0.40)$ & $3.71(0.44)$ & $0.13(-0.01$ to 0.27$)$ \\
Perceptions regarding patients in the emergency department & $3.98(0.43)$ & $3.73(0.45)$ & $0.25(0.11-0.39)$ \\
\hline
\end{tabular}

Note: *Data obtained from postclerkship surveys.

Abbreviations: $\mathrm{SD}$, standard deviation; $\mathrm{Cl}$, confidence interval. 
all sites for the statement "The ED team works well together". Some statements showed variability by site: 1) site A showed a decrease in ratings, while all other sites showed an increase in ratings regarding student perceptions on two statements ("EM physicians are compassionate" and "Patients in the ED are compliant with follow up"), and 2) student ratings at sites A and B (urban) increased, while at sites C and D (community) decreased for "... managing patients with behavioral problems".

We also analyzed pre- and postclerkship data by semesters (a semester is four blocks). Five statements were statistically significant: 1) students across all semesters increased in their responses to the statement "I have a role model in EM" $(P<0.001), 2)$ students across all semesters decreased in their responses to the statement "...treated with professionalism by other providers" $(P=0.01), 3)$ students' perceptions decreased in their responses regarding the view that ED patients "often need critical or ICU care" $(P=0.035)$, 4) students' perceptions regarding "EM physicians were generally satisfied with their career choice" increased with the first two semesters and decreased for the last semester $(P=0.002)$, and 5) students' responses to "My perception of EM has been influenced by the media" varied: the firstsemester rotation agreed with the statement, whereas the other semesters disagreed $(P=0.039)$.

In summary, the main results of this study are: 1) a mandatory senior EM clerkship did not change overall students' perceptions regarding ED patients, EM physicians, or EM as a desirable career choice; 2) overall, scores for statements related to the clerkship experiences decreased; 3) urban and community ED rotation sites may influence some student perceptions regarding ED patients and EM physicians; and 4) students who expressed an interest in EM consistently rated domains higher than those who were not interested in EM.

\section{Discussion}

Experiences during clerkships have the potential to influence, both positively and negatively, a student's perception of a medical specialty and affect their future career choices. ${ }^{6-10} \mathrm{We}$ found no significant difference regarding ratings of students' pre- and postclerkship perceptions of EM in most domains. This is in contrast to some studies in other disciplines that reported that students' perceptions were positively influenced by clinical rotations..$^{7-10,13}$ Since EM as a specialty is very well known and enjoys broad public and media interest, as demonstrated by the many popular ED-related television shows, students are likely to have high, preset expectations prior to an EM clerkship. ${ }^{5,14-17}$ Finding a significant difference in impact after a 4-week rotation is challenging under these circumstances. In contrast, in disciplines like child psychiatry and rural medicine, students may have had little exposure to or knowledge of the field prior to starting their clerkship, which offers greater opportunity to measure impact. ${ }^{10,13,14}$ Low, preset expectations may offer greater opportunity to find a significant difference. For example, in pediatrics students may perceive the specialty as "difficult, sad, and depressing because of the perceived vulnerability of young patients" or in general surgery, students may perceive the specialty as having a difficult lifestyle, a long pathway of residency, and stress, and thus offering the potential for positive perceptual changes postclerkship. ${ }^{6,9}$ Perhaps the high preset expectations for EM may have led to a realistic resetting of student expectations postclerkship and thus led to a drop in scores related to clinical experiences. As one student commented, "I thought people only came to the ED if their life was in danger ... I thought wrong. People abuse it! Complaints of earaches, sore throat, numb index finger..."

In addition, these high preset expectations of what an ED experience would be like may also have played a role in the overall decrease in scores for such statements as "... hands on learning experience" across all sites. For example, a student may be disappointed by the number of procedures he/ she is able to perform during the clerkship rotation. The site difference in rating results is likely explained by the clinical characteristics of and clinical experiences at the sites. Site A is a high-volume, urban, safety-net hospital with a level 1 trauma center and dedicated psychiatric emergency services. Students" perception that ED patients were "less compliant" at site A may be attributed to the fact that the site serves a high volume of patients who are underinsured or uninsured. Researchers in other disciplines have found that students completing clerkships in community settings had greater patient contact and valued their experiences more than those in a busy tertiary care center. ${ }^{18,19}$ Students also recognized that EM physicians at site A managed a high volume of patients with psychiatric emergencies. In spite of the perceptions of clerkship experiences at site A, it is the most popular site chosen for lottery assignment among those students interested in EM as a career. Notably, students across all sites finished their rotation with a positive perception of the way the ED team works well together. On analyses of free-response comments, we found overall positive comments regarding "great experiences", "great learning", and "great attending physicians" across sites.

As mentioned earlier, it was also clear from comments that students had certain preset expectations for this 
clerkship experience. The fact that they expected to see more "critically ill patients" and be engaged in more "procedures" may have impacted the ratings as a whole. We did not find major differences among semester blocks contrary to expectations. The first semester is when all the students who intend to apply for the EM match or have a very strong interest in EM rotate through the ED. The last semester is closer to when the residency-application process is nearing completion, and theoretically this group of students may have minimal interest in EM since it is not their intended career choice. However, it is interesting to note that mainly first-semester students reported that their EM perception was influenced by media. We can only speculate whether media influenced their career interest or whether an underlying interest in EM drew them to media such as the ER television show, in turn shaping expectations/perceptions regarding EM.

It is also not surprising to find that students interested in EM postclerkship have consistently more positive perceptions regarding the discipline, the EM physicians, and the ED patients. Among EM-interested students, there was a perception that the rotation was "easy". Irrespective of their ultimate interest, it is important to note that many students stated they had "a role model in EM" after their EM clerkship experience. This may have a future impact on perception of EM as a discipline in general. Findings of this pilot study suggest larger studies across teaching sites and geographic regions are needed to assess the preset expectations of medical students regarding EM and the impact of an EM clerkship on medical students and on the overall discipline.

\section{Limitations}

This was a single-site study with a relatively new EM residency program in a new academic EM department. As a result, students may have different experiences compared to medical schools with more established programs. Students' perceptions of EM may also vary depending on the location of their clinical sites, where the amounts of bedside teaching, hands-on experiences, and noninstructional activities may differ. Since we have a mandatory senior clerkship, many students have already selected their disciplines of interest prior to the EM clerkship, thereby affecting the results of the survey. This survey also may not be able to identify students interested in EM as a career through other pathways. As one student commented, "I may now want to do a pediatric EM fellowship after my pediatric residency." Finally, in the absence of a validated instrument in this field, we relied on student and EM faculty consensus to develop the survey.
Formal studies in larger populations may be needed to establish the reliability and validity of the instrument. Certain survey items might also benefit from greater clarity, eg, "an easy rotation" could have been reworded as "a meaningful rotation".

\section{Conclusion}

A mandatory senior EM clerkship did not change overall students' perceptions regarding ED patients, EM physicians, or career-related factors. Though EM interested students rated clerkship experiences higher than those not interested, there may be an overall decline in perceptions related to clerkship expectations and experiences. This pilot study did not find a major change in students' interests in EM as a specialty. Further larger multisite studies may help identify aspects of the field that affect a student's ultimate career choice.

\section{Disclosure}

The authors report no conflicts of interest in this work.

\section{References}

1. American Board of Emergency Medicine. History. Available from: https://www.abem.org/public/general-information/history. Accessed December 31, 2014

2. National Resident Matching Program. Results and data 2012. Available from: http://www.nrmp.org/data/resultsanddata2012. Accessed July 25, 2012.

3. Wald DA, Lin M, Manthey DE, Rogers RL, Zun LS, Christopher T. Emergency medicine in the medical school curriculum. Acad Emerg Med. 2010;17 Suppl 2:S26-S30.

4. Mathey DE, Ander DS, Gordon DC, et al. Emergency medicine clerkship curriculum: an update and revision. Acad Emerg Med. 2010;17:638-643.

5. Zun LS, Downey L. Is a third year clerkship in emergency medicine correlated with a career choice in emergency medicine? Teach Learn Med. 2004;16:14-17.

6. Ameh EA, Makama JG. Does general surgery clerkship make a future career in surgery more appealing to medical students? Afr Health Sci. 2010;10:292-296.

7. Fischel T, Manna H, Krivoy A, Lewis M, Weizman A. Does a clerkship in psychiatry contribute to changing medical students' attitudes towards psychiatry? Acad Psychiatry. 2008;32:147-150.

8. Cochran A, Paukert JL, Neumayer LA. Does a general surgery clerkship influence student perceptions of surgeons and surgical careers? Surgery. 2003;134:153-157.

9. Manal AA, Mohammed MS. Influence of the clinical rotation on intern attitudes toward pediatrics. Clin Pediatr. 2002;41:509-514.

10. Martin VL, Bennett DS, Pitale M. Medical students' perceptions of child psychiatry: pre- and post-psychiatry clerkship. Acad Psychiatry. 2005;29:362-367.

11. Mulcare MR, Suh EH, Tews M, Swan-Sein A, Pandit K. Third-year medical student rotations in emergency medicine: a survey of current practices. Acad Emerg Med. 2011;18 Suppl 2:S41-S47.

12. Avegno JL, Murphy-Lavoie H, Lofaso DP, Moreno-Walton L. Medical students' perceptions of an emergency medicine clerkship: an analysis of self assessment surveys. Int J Emerg Med. 2012;5:25.

13. Malloy E, Hollar D, Lindsey A. Increasing interest in child and adolescent psychiatry in the third-year clerkship: results from a post-clerkship survey. Acad Psychiatry. 2008;32(5):350-356. 
14. Blue AV1, Chessman AW, Geesey ME, Garr DR, Kern DH, White AW. Medical students' perceptions of rural practice following a rural clerkship. Fam Med. 2004;36:336-340.

15. Boyd JS, Clyne B, Reinert SE, Zink BJ. Emergency medicine career choice: a profile of factors and influences from the Association of American Medical Colleges (AAMC) graduation questionnaires. Acad Emerg Med. 2009;16:544-549.

16. Scott IM, Abu-Laban RB, Gowans MC, Wright BJ, Brenneis FR. Emergency medicine as a career choice: a descriptive study of Canadian medical students. CJEM. 2009;11:196-206.
17. Newton DA, Grayson MS, Thompson LF. The variable influence of lifestyle and income on medical students' career specialty choices: data from two US medical schools, 1998-2004. Acad Med. 2005;80: 809-814.

18. Dolmans DH, Wolfhagen HA, Essed GG, Scherpbier AJ, van derVleuten CP. Students' perceptions of time spent during clinical rotations. Med Teach. 2001;23:471-475

19. Worley P, Prideaux D, Strasser R, et al. What do medical students actually do on clinical rotations? Med Teach. 2004;26:594-598. 


\section{Supplementary material}

Clerkship Site___ Date___ Emergency Medicine Pre-Clerkship Survey Four Digit ID

The following questionnaire is being used to study the effect of our clerkship on student's perceptions of Emergency Medicine and Emergency Medicine physicians in general. Your answers will remain strictly anonymous and the four digit ID will be used only to track results for a before and after comparison. Please select a four digit number that you will remember at the end of your clerkship and write it in the space provided above. A proctor will ensure no two students have the same ID.

Please rate the extent to which you agree or disagree with the following statements. Circle the appropriate number using the scale below. We greatly appreciate your feedback!

\begin{tabular}{|c|c|c|c|c|c|}
\hline & $\begin{array}{l}\text { Strongly } \\
\text { disagree }\end{array}$ & Disagree & Neutral & Agree & $\begin{array}{l}\text { Strongly } \\
\text { agree }\end{array}$ \\
\hline \multicolumn{6}{|l|}{ An important factor when I choose a specialty is: } \\
\hline 1. Future lifestyle. & 1 & 2 & 3 & 4 & 5 \\
\hline 2. Future financial reward. & 1 & 2 & 3 & 4 & 5 \\
\hline 3. The opportunity to serve an underserved population. & 1 & 2 & 3 & 4 & 5 \\
\hline \multicolumn{6}{|l|}{ During the clerkship I expect: } \\
\hline 4. A hands on learning experience. & 1 & 2 & 3 & 4 & 5 \\
\hline 5. An easy rotation. & 1 & 2 & 3 & 4 & 5 \\
\hline 6. To be treated with professionalism by other providers. & 1 & 2 & 3 & 4 & 5 \\
\hline \multicolumn{6}{|l|}{ Emergency Medicine (EM) physicians: } \\
\hline 7. Have prestige in the local community. & 1 & 2 & 3 & 4 & 5 \\
\hline 8. Are respected by other physicians. & 1 & 2 & 3 & 4 & 5 \\
\hline 9. Make less income relative to other physicians & 1 & 2 & 3 & 4 & 5 \\
\hline 10. Have a predictable work schedule. & 1 & 2 & 3 & 4 & 5 \\
\hline 11. Have a flexible work schedule. & 1 & 2 & 3 & 4 & 5 \\
\hline 12. Will have job security in the future. & 1 & 2 & 3 & 4 & 5 \\
\hline 13. Are generally satisfied with their career choice. & 1 & 2 & 3 & 4 & 5 \\
\hline 14. Are compassionate providers. & 1 & 2 & 3 & 4 & 5 \\
\hline 15. Have adequate patient contact. & 1 & 2 & 3 & 4 & 5 \\
\hline 16. Use technical skills and procedures. & 1 & 2 & 3 & 4 & 5 \\
\hline 17. Provide primary healthcare to patients (eg, BP management) & 1 & 2 & 3 & 4 & 5 \\
\hline \multicolumn{6}{|l|}{ Emergency Medicine physicians: } \\
\hline 18. Deal with patient behavioral problems. & 1 & 2 & 3 & 4 & 5 \\
\hline 19. Are susceptible to burn-out. & 1 & 2 & 3 & 4 & 5 \\
\hline \multicolumn{6}{|l|}{ Patients in the Emergency Department (ED): } \\
\hline 20. Have a variety of ailments. & 1 & 2 & 3 & 4 & 5 \\
\hline 21. Often need critical (ICU level) care. & 1 & 2 & 3 & 4 & 5 \\
\hline 22. Experience improved symptoms while in the ED. & 1 & 2 & 3 & 4 & 5 \\
\hline 23. Are compliant with their follow up treatment. & 1 & 2 & 3 & 4 & 5 \\
\hline 24. Are from a variety of age groups. & 1 & 2 & 3 & 4 & 5 \\
\hline 25. My perception of EM has been influenced by the media. & 1 & 2 & 3 & 4 & 5 \\
\hline 26. I have a role model in Emergency Medicine. & 1 & 2 & 3 & 4 & 5 \\
\hline 27. The ED team works well together. & 1 & 2 & 3 & 4 & 5 \\
\hline 28. The ED is a low stress place to work. & 1 & 2 & 3 & 4 & 5 \\
\hline 29. I am confident EM will be my future specialty. & 1 & 2 & 3 & 4 & 5 \\
\hline
\end{tabular}

\section{Please tell us about yourself:}

Age:

Gender: - Male $\quad$ Female

Have you ever been a patient in the ED? - Yes - No

Please give the approximate number of work/volunteer hours you have previously spent in any emergency department:

Do you have a relative that works in an ED? - Yes - No

If yes, they work as a: - Physician - PA - APN - RN • ED Tech - CNA • Other, please specify

Do you have a relative that is a Physician in another specialty? Y Yes - No

If so, please specify

What are your top three specialty choices?

Thank you!

Figure SI Emergency medicine pre-clerkship survey.

Abbreviations: ICU, intensive care unit; BP, blood pressure; PA, physician assistant; APN, advanced practice nurse; RN, registered nurse; CNA, certified nursing assistant. 
Advances in Medical Education and Practice

Dovepress

\section{Publish your work in this journal}

Advances in Medical Education and Practice is an international, peerreviewed, open access journal that aims to present and publish research on Medical Education covering medical, dental, nursing and allied health care professional education. The journal covers undergraduate education, postgraduate training and continuing medical education

including emerging trends and innovative models linking education, research, and health care services. The manuscript management system is completely online and includes a very quick and fair peer-review system. Visit http://www.dovepress.com/testimonials.php to read real quotes from published authors.

Submit your manuscript here: http://www.dovepress.com/advances-in-medical-education-and-practice-journal 